\title{
Data Fusion of Electronic Nose and Electronic Tongue for Detection of Mixed Edible-Oil
}

\author{
Hong Men, Donglin Chen, Xiaoting Zhang, Jingjing Liu, and Ke Ning \\ School of Automation Engineering, Northeast Dianli University, Jilin 132012, China \\ Correspondence should be addressed to Hong Men; menhong_china@hotmail.com
}

Received 10 April 2014; Accepted 12 May 2014; Published 26 May 2014

Academic Editor: Jesús Lozano

Copyright (C) 2014 Hong Men et al. This is an open access article distributed under the Creative Commons Attribution License, which permits unrestricted use, distribution, and reproduction in any medium, provided the original work is properly cited.

For the problem of the waste of the edible-oil in the food processing, on the premise of food security, they often need to add new edible-oil to the old frying oil which had been used in food processing to control the cost of the production. Due to the fact that the different additive proportion of the oil has different material and different volatile gases, we use fusion technology based on the electronic nose and electronic tongue to detect the blending ratio of the old frying oil and the new edible-oil in this paper. Principal component analysis (PCA) is used to distinguish the different proportion of the old frying oil and new edible-oil; on the other hand we use partial least squares (PLS) to predict the blending ratio of the old frying oil and new edible-oil. Two conclusions were proposed: data fusion of electronic nose and electronic tongue can be used to detect the blending ratio of the old frying oil and new edible-oil; in contrast to single used electronic nose or single used electronic tongue, the detection effect has increased by using data fusion of electronic nose and electronic tongue.

\section{Introduction}

In the process of fried food manufacturing [1-4], the consumption of the edible-oil [5-7] is very large. If they replace all the old frying oil with the new edible-oil after the production every time, the oil will be wasted and the cost of production will be increased. On the premise of food security, a process of the production is to take some old frying oil out and then add appreciable proportion of the new edible-oil to solve the problem. This can improve the utilization rate of the edible-oil and reduce the cost of the production. But when the concentration of the old frying oil is too high, the oil contacts with the oxygen in the air and creates reactions such as hydrolysis, oxidation, and polymerization which will lead to the increase of oil viscosity, peroxide value increase, and a series of harmful carcinogens [8]. So it is very important to detect the blending ratio of the old frying oil and the new edible-oil accurately.

Traditional methods of oil detection include conventional physical and chemical index analysis $[9,10]$, cholesterol assays [11], conductivity testing [12-16], and headspace gas chromatography coupled to composition testing [17, 18]. Some achievements have been made. Wang et al. analyzed the edible-oil by detecting the conductivity of the adulterated edible-oil [19]. Zhang et al. distinguished hogwash oil in edible vegetable oil by detecting the content of the cholesterol [20]. Wang et al. detected the phthalates of the edible-oil by using GC-MS [21]. However, the methods above are quite complex, of long time testing, of low sensitivity, and of high cost. Therefore, it is very important to find a method with a quick and reliable detection.

In recent years, the electronic nose and the electronic tongue as two kinds of fast, efficient, nondestructive, and reliable testing methods were used in the detection of edibleoil. Hai and Wang [22] detected the camellia oil and sesame oil mixed with the soybean oil by using the portable electronic nose of PEN2 and distinguished different oil. Cosio et al. [23] analyzed the quality of olive with the electronic nose. Zhang et al. [24] realized rapid detection of the camellia seed oil mixed with palm oil by using the electronic tongue. Hui et al. [25] realized distinguishing of different kinds of edible-oil with the electronic tongue.

The different additive proportion of the oil has different material and different volatile gases. Using electronic nose or electronic tongue single can only provide partial information of the samples, which may cause inaccuracy of the detection. 


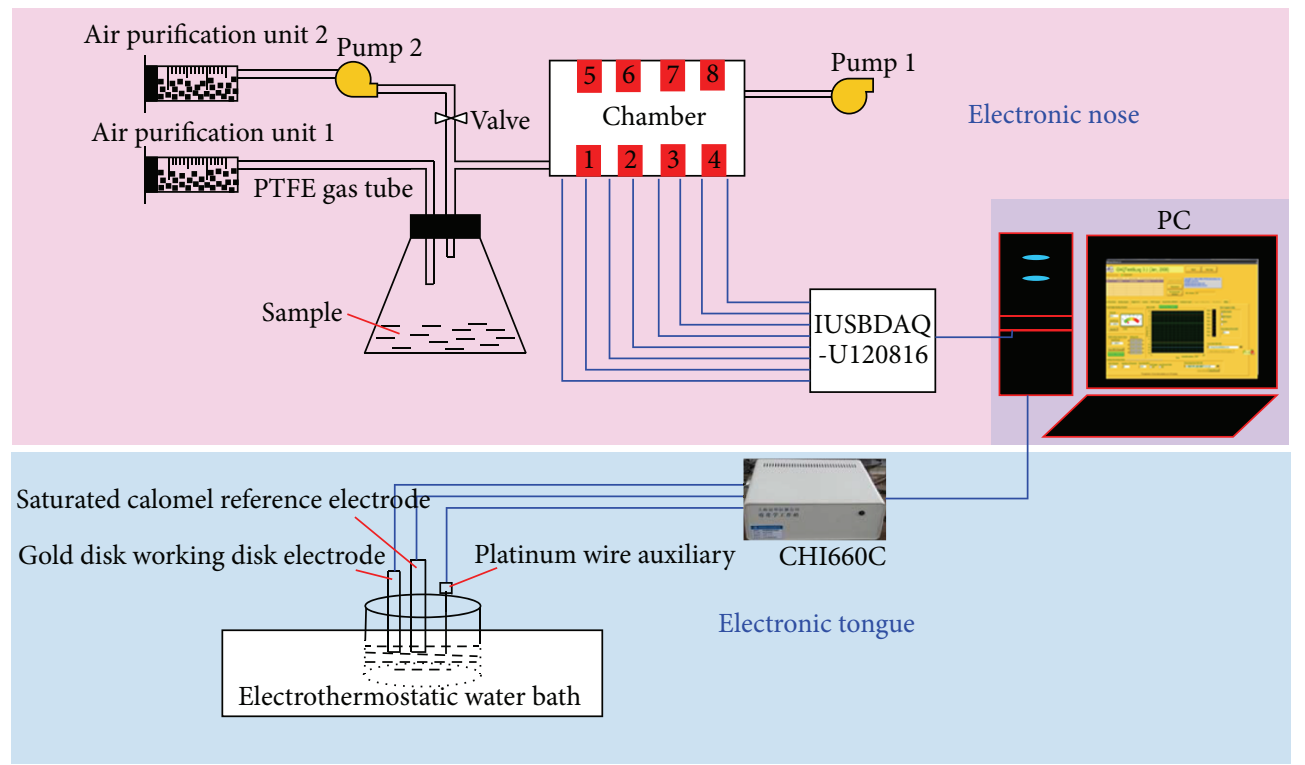

FIGURE 1: Block diagram of the fusion system.

TABLE 1: Characters of sensors.

\begin{tabular}{lccc}
\hline Number & Sensor name & Sensitive gas & Detection range (mg/L) \\
\hline 1 & TGS813 & Butane, propane, and methane & $500-10000$ \\
2 & TGS821 & Hydrogen & $30-1000$ \\
3 & TGS822 & Alcohol & $50-5000$ \\
4 & TGS825 & Hydrogen sulfide & $5-100$ \\
5 & TGS826 & Ammonia & $30-300$ \\
6 & TGS830 & R-113, alcohol, and hydrogen & $100-3000$ \\
7 & TGS831 & R-21 and R-22 & $100-3000$ \\
8 & TGS832 & R-134a & $100-3000$ \\
\hline
\end{tabular}

Therefore, we use fusion technology based on the electronic nose and electronic tongue to detect the blending ratio of the old frying oil and the new edible-oil in this paper. Principal component analysis (PCA) [26, 27] is used to distinguish the different proportion of the old frying oil and new edible-oil, and partial least squares (PLS) method [28, 29] is used to predict the blending ratio of the old frying oil and new edibleoil.

\section{Fusion System}

Two subsystems are included in the fusion system, that is, the electronic nose system and the electronic tongue system. Figure 1 shows the block diagram of the fusion system.

2.1. Electronic Nose. In this paper, the electronic nose system is designed with dynamic headspace sampling method. This system consists of three main parts: gas supply and transfer unit; sensor array and the chamber unit; data acquisition and processing unit [30].

The first unit consists of air purification, headspace of the vials, and pumps. This unit is divided into two stages: gas injection and cleaning the system. In the first stage, the volatiles of sample are transported by the air which is filtered by the active carbon to obtain zero gas. In this phase, pump 1 sucks the sample gas compounds to the sensor chamber to be analyzed by the array of sensors and pump 2 is closed. In the injection phase, both pumps are open. A common power supply of $12 \mathrm{~V}$ is used for both the working voltage of pump 2 and the voltage applied to the voltage divider formed by the sensors and the load resistances. A common power supply of $5 \mathrm{~V}$ is used for both the working voltage of pump 1 and the heater voltage of the sensors. Since the flow rate of pump increases as the working voltage increases, the flow rate of pump 2 is higher than that of pump 1. The cleaning air flow of pump 2 is used to clean the system. Due to the higher flow rate of pump 2, the original gas flow direction at the inlet is inverted.

Eight TGS Figaro gas sensors, TGS8XX (XX = 13, 21, 22, $25,26,30,31,32$ ) obtained from Figaro Engineering, Inc., have been used in this electronic nose. Table 1 lists characters of all the sensors. They have high sensitivity, high stability, and long life; they even have higher output signal and simple conditioning circuit. When the gas concentration increases, the resistance of the sensor decreases. Considering the memorability of the chamber to the sample, the chamber is made 
of cardboard which is covered by polytetrafluoroethylene (PTFE). PTFE is a thermoplastic polymer; the melting point is $327^{\circ} \mathrm{C}\left(621^{\circ} \mathrm{F}\right)$, the density is $2.2 \mathrm{~g} / \mathrm{cm}^{3}$, and the friction coefficient is $0.05 \sim 0.10$ [31]. The adsorption of PTFE for gas is weak. So polytetrafluoroethylene was chosen as the material of the chamber to reduce the gas adsorption of the chamber. In the third unit, we choose IUSBDAQ-U120816 to collect the data. It can convert the output analog voltage signals into digital signals and send them to the computer.

\subsection{Electronic Tongue}

2.2.1. Voltammetric Electronic Tongue System. Electronic tongue is a new kind of analysis testing instrument, which is also known as intelligent bionic system of taste. Common type of electronic tongue contains potentiometric electronic tongue, electronic tongue based on the impedance spectrum sensors, and voltammetry electronic tongue. In this paper, we build a voltammetry electronic tongue system which consists of sensor array, electrochemical workstation, and computer. The sensor array is composed of a working electrode, a reference electrode, and an auxiliary electrode.

Working electrode, which is also called sensing electrode, can cause the obvious variation of component concentration which needs to be tested in the testing process. Reference electrode consists of a constant component phase. The electrode potential of the reference electrode did not change in the process of measuring. The change of the electromotive force of cell reflects the variation of electrode potential of working electrode. The reference electrode and the working electrode pole constitute the cell, which forms a current loop. There is a constant voltage system between the working electrode and the reference electrode to keep the stability of the voltage in the liquid system. The output of the current in the circuit would be tested as the signals. In this paper, we choose a gold disk working electrode, a platinum wire auxiliary electrode, and a saturated calomel reference electrode. The electrodes are connected with the electrochemical workstation and then inserted into the sample solutions when we do the experiment. The CHI660C electrochemical workstation produces electrical pulses, collects the signal, and stores the signal to the computer at the same time.

2.2.2. Cyclic Voltammetry. Cyclic voltammetry is commonly used in the electrochemical study. The method controls the electrode potential with different rates, a triangular wave scanning once or more with time. Different electrode potential contributes the electrode to different oxidation and reduction reaction and records the current-voltage curve. In this paper, we use cyclic voltammetry for testing.

\section{Experiments}

3.1. Sample Collection. We choose golden dragon soybean oil as samples, which were purchased at a local supermarket. And we choose repeatedly fried potato old oil as old frying oil. Nine kinds of different concentrations of frying oil were configured as testing samples. Table 2 lists all of these.
TABLE 2: Samples for frying oil.

\begin{tabular}{lccc}
\hline Number & $\begin{array}{c}\text { Percent of } \\
\text { frying oil (\%) }\end{array}$ & $\begin{array}{c}\text { Content of } \\
\text { frying oil } \\
(\mathrm{mL})\end{array}$ & $\begin{array}{c}\text { Content of } \\
\text { good oil }(\mathrm{mL})\end{array}$ \\
\hline 1 & 100 & 20 & 0 \\
2 & 50 & 10 & 10 \\
3 & 25 & 5 & 15 \\
4 & 12.5 & 2.5 & 17.5 \\
5 & 6.25 & 1.25 & 18.75 \\
6 & 3 & 0.6 & 19.4 \\
7 & 2 & 0.4 & 19.6 \\
8 & 1 & 0.2 & 19.8 \\
9 & 0 & 0 & 20 \\
\hline
\end{tabular}

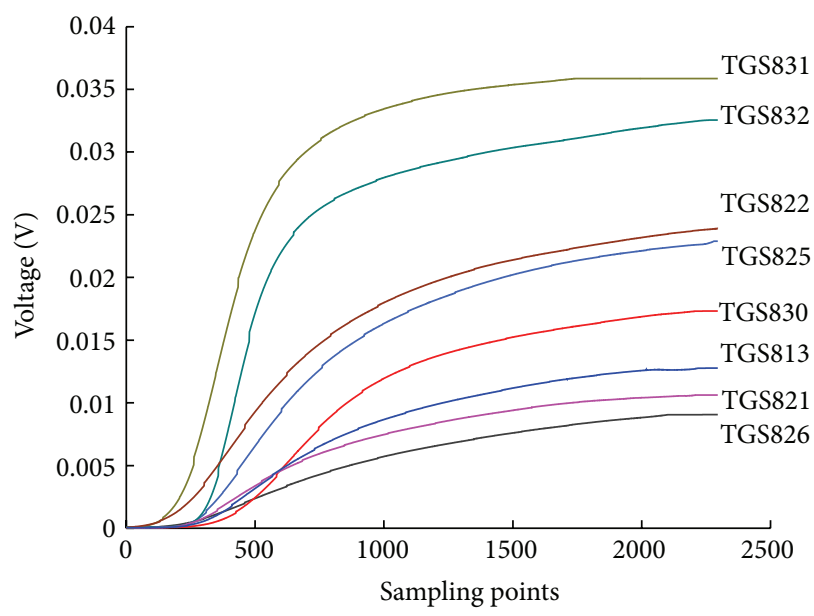

FIGURE 2: Electronic nose response signal.

3.2. Measurement Using Electronic Nose. The detection of old frying oil is taken using the dynamic headspace technique. The laboratory condition for testing is under $20^{\circ} \mathrm{C} \pm 2^{\circ} \mathrm{C}$ and $65 \pm 5 \%$ relative humidity. Measurements are divided into three steps. First, a flow of zero gases goes through the chamber for 30 minutes to get the sensor signal stability; secondly, we get the mixture oil into the $100 \mathrm{~mL}$ glassware, the pump is used to place the gas into the chamber, and the response time of the sensors was approximately 4 minutes; thirdly, the chamber is cleaned with the zero gases for 20 minutes. Not until the sensors equilibrated, can a new measurement be initiated. Each sample was measured for 8 times. After all the tests, 72 groups of data were received. The 2250 point of sample signal is taken as the analysis signal of the electronic nose system. Figure 2 shows one of the measurements.

3.3. Measure Using the Electronic Tongue. The detection of old frying oil is taken using the voltammetry electronic tongue. Measures are divided into four steps. First, take $20 \mathrm{~mL}$ of the frying oil, dilute with $50 \mathrm{~mL}$ petroleum ether, mixed with $40 \mathrm{~mL}$ distilled water, use ultrasonic stirring, and then wait for static layers; secondly, three electrodes are immersed 


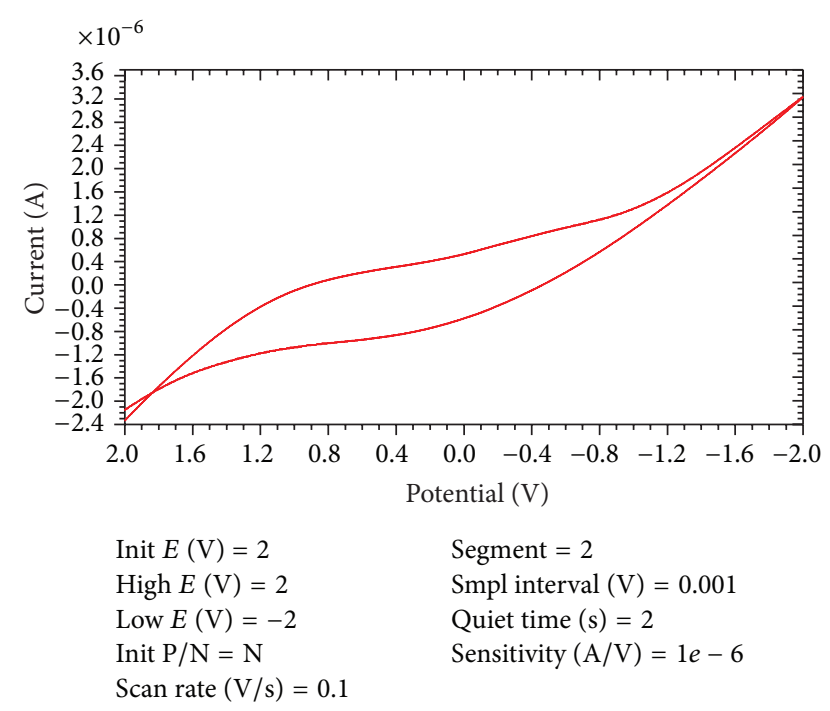

FIGURE 3: Electronic tongue response signal.

with alcohol for $6 \mathrm{~min}$, cleaned with deionized water, dried with filter paper, and then fixed with CHI660C; thirdly, parameters are set after starting $\mathrm{CHI} 660 \mathrm{C}$, and the cyclic voltammetry is used to test; finally, after testing, clean the beaker and the electrodes. Each sample is measured for 8 times. Repeat the steps; after all the tests, 72 groups of data were received. And we choose the currents corresponding to $1.3 \mathrm{~V}, 1 \mathrm{~V}, 0.7 \mathrm{~V}, 0.4 \mathrm{~V}, 0.1 \mathrm{~V},-0.2 \mathrm{~V}$, and $-0.5 \mathrm{~V}$, respectively, as the analysis signal of the electronic tongue system. Figure 3 shows one of the measurements. Two stages of reaction are represented by the current-voltage curve in Figure 3, which is also known as the cyclic voltammetry curve. The first stage is the reduction process of the electroactive substance, and the current increases when the electrode potential reduces. The second stage is the oxidation process of the reduction product, and the current reduces when the electrode potential increases.

\section{Data Processing and Analyzing}

4.1. Principal Component Analysis. PCA is a dimensionality reduction method. The aim of PCA is to find a set of vectors to explain the variance of the data in the data space as far as possible. The dimension of the original data is reduced by a special matrix. A set of scattered information is used to form a few principal components, so as to achieve the purpose of dimension reduction. Each principal component is a linear combination of the original variables, mutually orthogonal relation between main components. When the cumulative contribution rate of the anterior principal components is more than $85 \%$, they are used to represent the samples.

In this paper, PCA is used to deal with the characteristic data of the electronic nose, the characteristic data of the electronic tongue, and the fusion data of the two systems. As for the electronic nose, maximum values are chosen as the features. There are 8 MOS sensors in the electronic nose system, so the number of features is 8 in each sample. As for

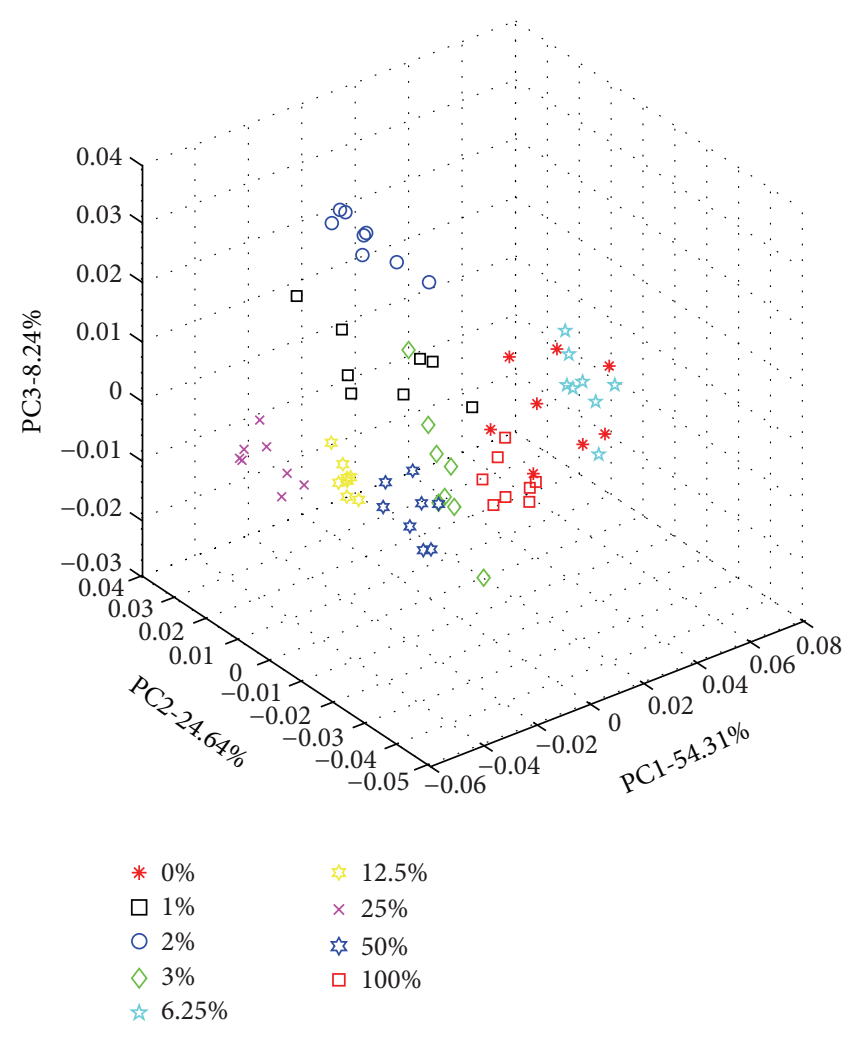

FIGURE 4: PCA plot of electronic nose system.

the electronic tongue, the current values corresponding to 7 voltage values in the cyclic voltammetry curve are chosen as the features. As for the fusion system, the fusion of characteristics which is a kind of data fusion is used to realize the fusion of electronic nose system and the electronic tongue system. The characteristic vectors of both systems separately are used to form high dimension data as the new characteristics of the fusion system. Thanks to the fact that cumulative contribution rate of the first two principal components is less than $85 \%$, we choose the first three principal components as the signals. Figure 4 , for the data set of electronic nose, shows that $\mathrm{PCl}$ can explain $54.13 \%$ of the variance, PC2 can explain $24.64 \%$ of the variance, and PC3 can explain $8.24 \%$ of the variance. Figure 5 , for the data set of the electronic tongue, shows that $\mathrm{PCl}$ can explain 69.93\% of the variance, PC2 can explain $29.74 \%$ of the variance, and PC 3 can explain $0.25 \%$ of the variance. Figure 6 , for the fused data sets of two systems, shows that PC1 can explain $61.79 \%$ of the variance, $\mathrm{PC} 2$ can explain $18.12 \%$ of the variance, and PC3 can explain $10.29 \%$ of the variance.

In Figure 4, we can see that the $50 \%$ and $100 \%$ contents of old frying oil are separated well in the electronic nose but the others cannot be separated well. In Figure 5, we can see that the $100 \%, 50 \%, 25 \%$, and $12.5 \%$ contents of old frying oil are separated well in the electronic tongue but the others cannot be separated well. In Figure 6, we can see that almost all the samples can be separated well in the fusion system by using PCA. 


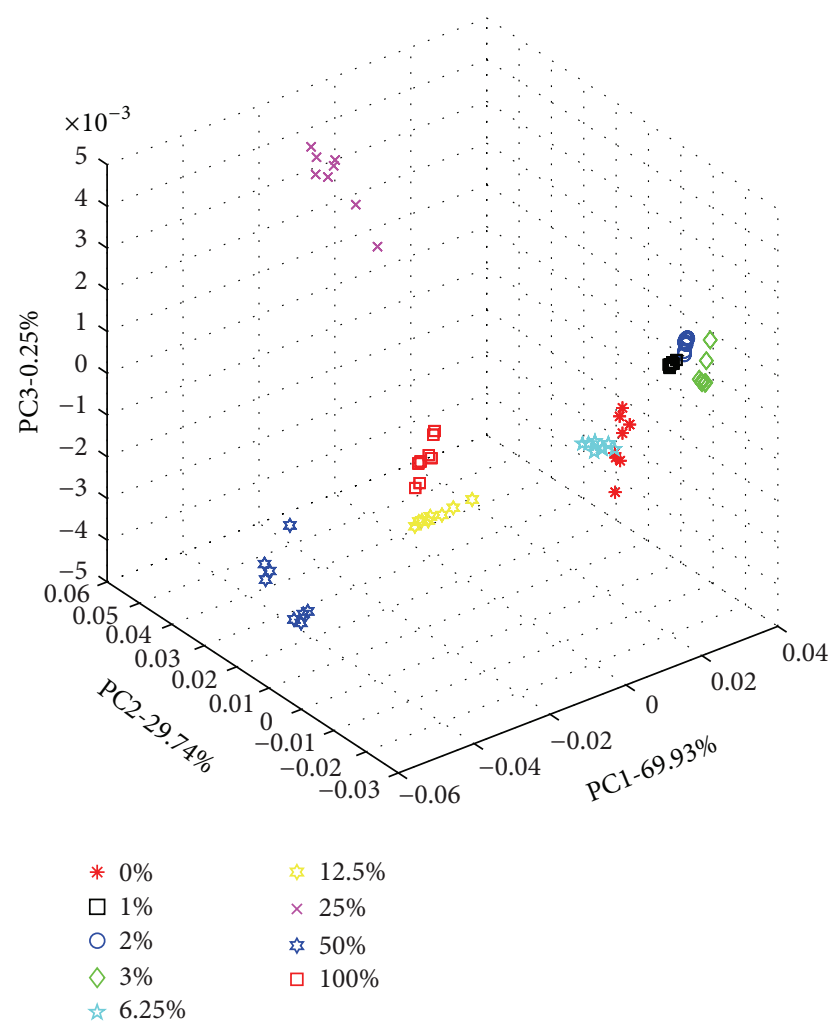

Figure 5: PCA plot of electronic tongue system.

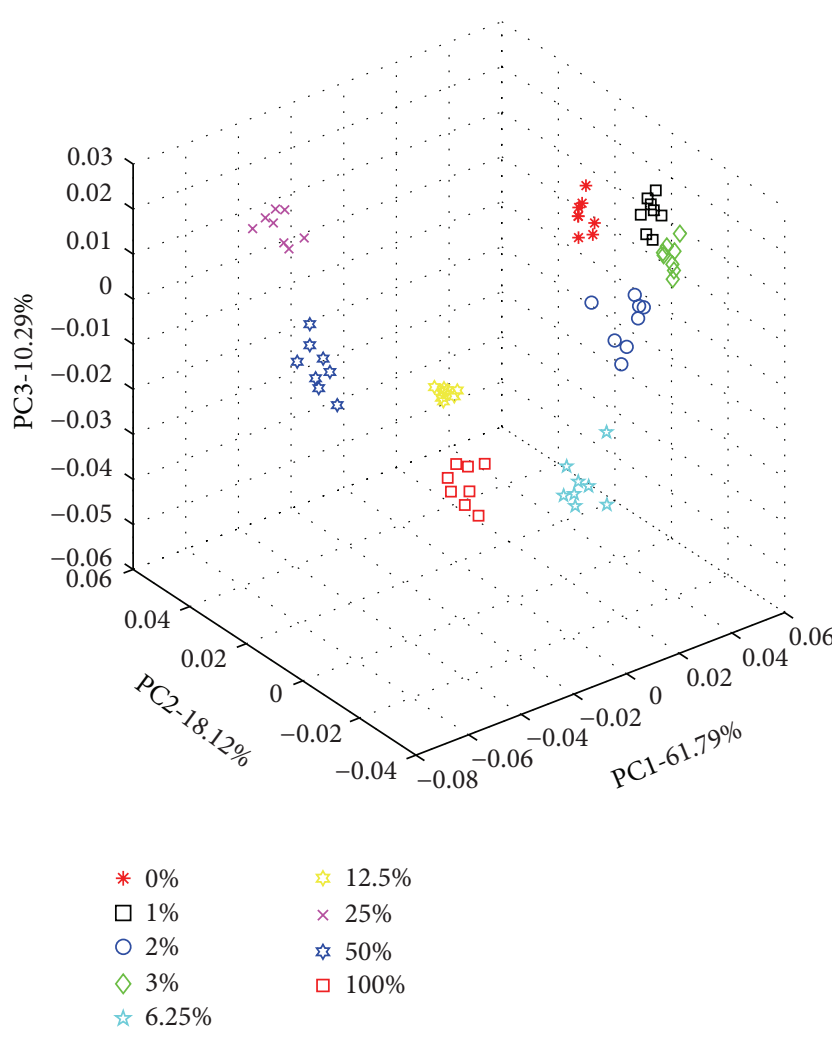

FIGURE 6: PCA plot of data fusion system.

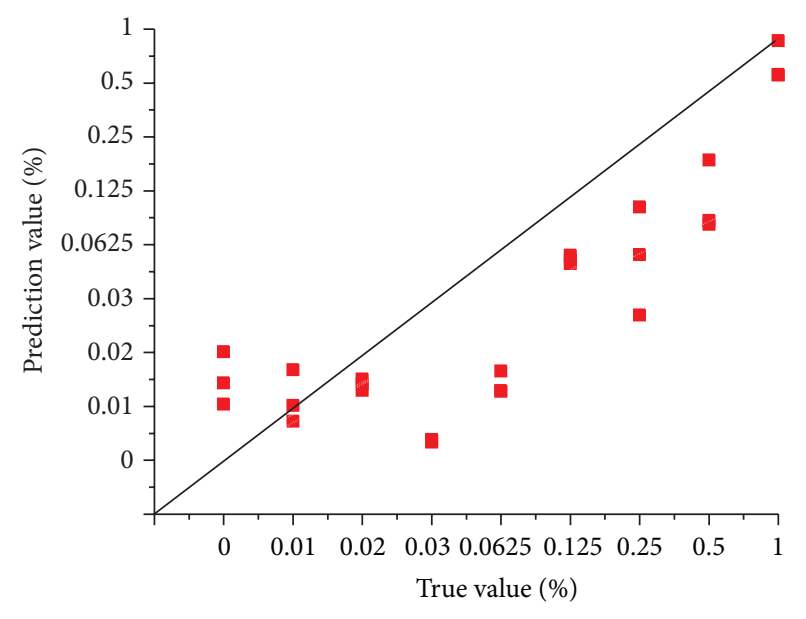

Figure 7: PLS plot of electronic nose system.

4.2. Partial Least Squares. The method of partial least squares regression, which is also called PLS, is a new kind of multivariate statistics analysis method. It mainly studies the dependent variable regression modeling to the dependent variable. PLS is used more effectively when the dependent variables have higher linear correlation. In addition, PLS is better to solve the problem which is that the sample number is less than the number of variables. PLS is one of synthesis and screening the information methods. It is a bilinear model based on the $X$ (independent variables) and $Y$ (dependent variable) matrix. It can be seen as the external relationships and internal relationship. It is used to reflect the relationship between independent variable and dependent variable.

In this paper, PLS is used to predict the proportion of the old frying oil. Different proportions of the old frying oil, such as $100 \%, 50 \%, 25 \%, 6.25 \%, 3 \%, 2 \%$, and $1 \%$, are analyzed. Figure 7 shows the prediction of the old frying oil proportion with the electronic nose system. The correlation coefficient we get is 0.84342 , and the request of the correlation coefficient for PLS model is above 0.8 , so the model is effective. The results show that the error is $12.099 \%$. Figure 8 shows the prediction of the old frying oil proportion with the electronic tongue system. The correlation coefficient we get is 0.96289 and the error is $4.65 \%$. Figure 9 shows the prediction of the old frying oil proportion with the fused data set of two systems. The method of data fusion is the same as previously mentioned. The correlation coefficient we get is 0.9895 and the error is $2.93 \%$. We can say that the prediction effect of the fused data set of two systems is better than single using of electronic nose or electronic tongue.

\section{Conclusions}

The concept of data fusion was applied to detect the content of the frying oil in this paper. We use the merging system of the electronic nose system based on dynamic headspace method and the electronic tongue system. PCA and PLS are used in the characteristics of the electronic nose, the feature data of the electronic tongue, and the fused data of two systems. The 


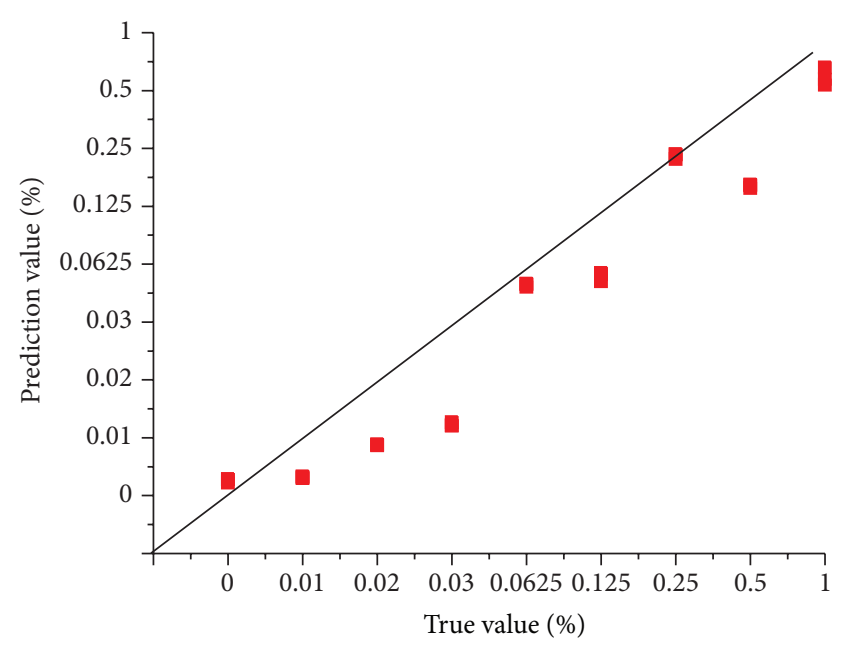

Figure 8: PLS plot of electronic tongue system.

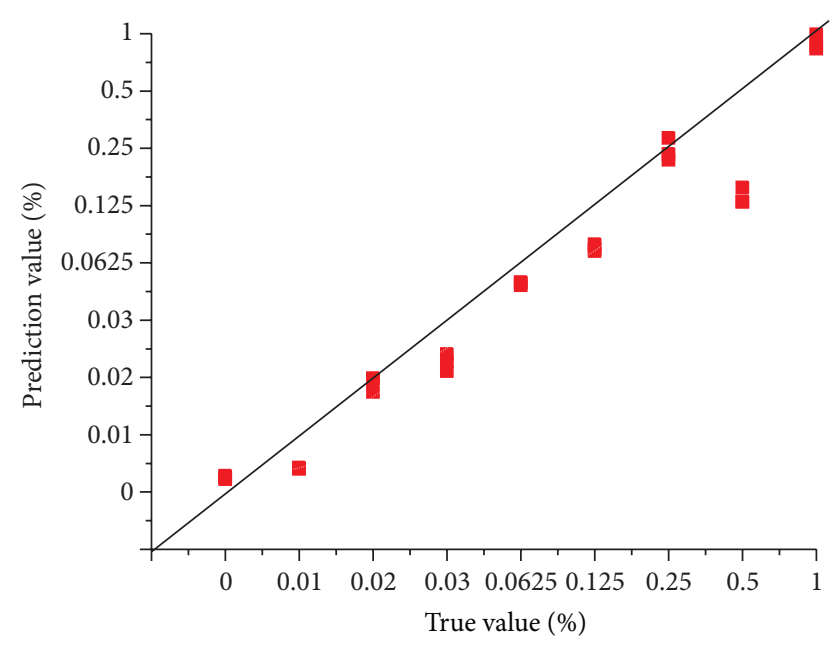

FIgURE 9: PLS plot of data fusion.

results show that when we use PCA, the effect of detection using the electronic tongue system is better than the effect of detection with the electronic nose system, but when we fuse the data of two systems, the recognition rate improved significantly. We can see that when we use PLS, the effect of prediction using the electronic tongue system is better than the effect of prediction using the electronic tongue and the prediction error reduced from $12.099 \%$ to $4.65 \%$, but when we fuse the data of two systems, the prediction effect improved and the prediction error reduced to $2.93 \%$. In summary, we can use the data fusion of electronic nose and electronic tongue to detect the content of the frying oil and the method is more effective than single using of the electronic nose system and single using of the electronic tongue system.

\section{Conflict of Interests}

The authors declare that there is no conflict of interests regarding the publication of this paper.

\section{Acknowledgments}

This work was supported by Jilin Province Education Department Research Program of China (no. 2012-100), Jilin City Science \& Technique Program of China (no. 201112209), and Jilin Province Science \& Technique Program of China (no. 20130101053JC) to Hong Men.

\section{References}

[1] M. Nikolaou, "Control of snack food manufacturing systems," Control Systems, vol. 26, no. 4, pp. 40-53, 2006.

[2] J. A. Mumith, C. Makatsoris, and T. G. Karayiannis, "Design of a thermoacoustic heat engine for low temperature waste heat recovery in food manufacturing: a thermoacoustic device for heat recovery," Applied Thermal Engineering, vol. 65, no. 1, pp. 588-598, 2014.

[3] K. N. Jordan, K. Hunt, and E. M. Fox, "10-Troubleshooting the environmental source of contamination with Listeria monocytogenes in a typical small food manufacturing plant in Ireland," in Case Studies in Food Safety and Authenticity, pp. 95-101, 2012.

[4] K. Grob, J. Stocker, and R. Colwell, "Assurance of compliance within the production chain of food contact materials by good manufacturing practice and documentation-part 1: legal background in Europe and compliance challenges," Food Control, vol. 20, no. 5, pp. 476-482, 2009.

[5] J. He, W. Xu, Y. Shang et al., "Development and optimization of an efficient method to detect the authenticity of edible oils," Food Control, vol. 31, no. 1, pp. 71-79, 2013.

[6] M. Wrona, D. Pezo, and C. Nerin, "Rapid analytical procedure for determination of mineral oils in edible oil by GC-FID," Food Chemistry, vol. 141, no. 4, pp. 3993-3999, 2013.

[7] T. Payanan, N. Leepipatpiboon, and P. Varanusupakul, "Lowtemperature cleanup with solid-phase extraction for the determination of polycyclic aromatic hydrocarbons in edible oils by reversed phase liquid chromatography with fluorescence detection," Food Chemistry, vol. 141, no. 3, pp. 2720-2726, 2013.

[8] M. F. Zhao, Z. W. Zhang, and N. Wang, "Identification model in frying oil based on interval partial least squares regression analysis," Laser Journal, vol. 33, no. 5, pp. 38-40, 2012.

[9] F. H. Poliseli-Scopel, M. Hernández-Herrero, B. Guamis, and V. Ferragut, "Comparison of ultra high pressure homogenization and conventional thermal treatments on the microbiological, physical and chemical quality of soymilk," LWT-Food Science and Technology, vol. 46, no. 1, pp. 42-48, 2012.

[10] B. Liu, C. Tu, S. Hu, M. Gumpertz, and J. B. Ristaino, "Effect of organic, sustainable, and conventional management strategies in grower fields on soil physical, chemical, and biological factors and the incidence of Southern blight," Applied Soil Ecology, vol. 37, no. 3, pp. 202-214, 2007.

[11] D. Shao, G. E. Bartley, W. Yokoyama, Z. Pan, H. Zhang, and A. Zhang, "Plasma and hepatic cholesterol-lowering effects of tomato pomace, tomato seed oil and defatted tomato seed in hamsters fed with high-fat diets," Food Chemistry, vol. 139, no. 1-4, pp. 589-596, 2013.

[12] Y. D. Yang, Q. H. Li, X. Z. Yu, X. M. Chen, and Y. G. Wang, "A novel method for determining peroxide value of edible oils using electrical conductivity," Food Control, vol. 39, pp. 198-203, 2014. 
[13] M. Kole and T. K. Dey, "Role of interfacial layer and clustering on the effective thermal conductivity of $\mathrm{CuO}$-gear oil nanofluids," Experimental Thermal and Fluid Science, vol. 35, no. 7, pp. 1490-1495, 2011.

[14] A. Makahleh and B. Saad, "Flow injection determination of free fatty acids in vegetable oils using capacitively coupled contactless conductivity detection," Analytica Chimica Acta, vol. 694, no. 1-2, pp. 90-94, 2011.

[15] B. Wang, X. Wang, W. Lou, and J. Hao, "Thermal conductivity and rheological properties of graphite/oil nanofluids," Colloids and Surfaces A: Physicochemical and Engineering Aspects, vol. 414, pp. 125-131, 2012.

[16] L. Nuñez, X. Cetó, M. I. Pividori, M. V. B. Zanoni, and M. del Valle, "Development and application of an electronic tongue for detection and monitoring of nitrate, nitrite and ammonium levels in waters," Microchemical Journal, vol. 110, pp. 273-279, 2013.

[17] M. Hajimahmoodi, Y. Vander Heyden, N. Sadeghi, B. Jannat, M. R. Oveisi, and S. Shahbazian, "Gas-chromatographic fattyacid fingerprints and partial least squares modeling as a basis for the simultaneous determination of edible oil mixtures," Talanta, vol. 66, no. 5, pp. 1108-1116, 2005.

[18] S. K. Jha and R. D. S. Yadava, "Denoising by singular value decomposition and its application to electronic nose data processing," IEEE Sensors Journal, vol. 11, no. 1, pp. 35-44, 2011.

[19] F. Y. Wang, X. Z. Yu, M. M. Lv et al., "Fast qualitative and semi-quantitative analysis of hogwash oil by conductivity," Food Science, vol. 32, no. 18, pp. 304-307, 2011.

[20] R. Zhang, L. Y. Zhu, T. Fan et al., "Distinguish hogwash oil in edible vegetable oil by determination of cholesterol content," China Oil, vol. 31, no. 5, pp. 65-67, 2006.

[21] S. Wang, K. Wang, H.-P. Zhu, G.-Z. Fang, J. Chen, and J.-J. Song, "Study of phthalates detection in oil by gas chromatographymass spectrometry," Food Research and Development, vol. 31, no. 9, pp. 127-130, 2010.

[22] Z. Hai and J. Wang, "Detection of adulteration in camellia seed oil and sesame oil using an electronic nose," European Journal of Lipid Science and Technology, vol. 108, no. 2, pp. 116-124, 2006.

[23] M. Stella Cosio, S. Benedetti, S. Buratti, M. Scampicchio, and S. Mannino, "Chapter 60-Application of the electronic nose in olive oil analyses," in Olives and Olive Oil in Health and Disease Prevention, pp. 553-559, 2010.

[24] H. Zhang, S. L. Zhao, W. J. Chen et al., "Rapid detection of adulterated palm oil in camellia seed oil by electronic tongue," Food Science, vol. 34, no. 14, pp. 218-222, 2013.

[25] Y. B. Hui, Q. Wang, L. Wang et al., "Discrimination of different edible vegetable oils by electronic tongue," China Oil, vol. 38, no. 6, pp. 49-54, 2013.

[26] C. J. Liu, "Gabor-based kernel PCA with fractional power polynomial models for face recognition," IEEE Transactions on Pattern Analysis and Machine Intelligence, vol. 26, no. 5, pp. 572581, 2004.

[27] D. M. Karabacak, L. Sieben-Xu, M. Vandecasteele et al., "Toward a miniaturized low-power micromechanical electronic nose," IEEE Sensors Journal, vol. 12, no. 11, pp. 3184-3188, 2012.

[28] M. Sarstedt, M. R. Christian, D. Smith et al., "Partial least squares structural equation modeling (PLS-SEM): a useful tool for family business researchers," Journal of Family Business Strategy, vol. 5, no. 1, pp. 105-1155, 2014.

[29] V. Cariou, S. Verdun, and E. M. Qannari, "Quadratic PLS regression applied to external preference mapping," Food Quality and Preference, vol. 32, pp. 28-34, 2014.
[30] Z. Haddi, H. A. Alami, N. E. Bari et al., "Electronic nose and tongue combination for improve classification of Moroccan virgin olive oil profiles," Food Research International, vol. 54, no. 2, pp. 1488-1498, 2013.

[31] X.-Y. Tian, Q. Cai, and Y.-M. Zhang, "Rapid classification of hairtail fish and pork freshness using an electronic nose based on the PCA method," Sensors, vol. 12, no. 1, pp. 260-277, 2012. 

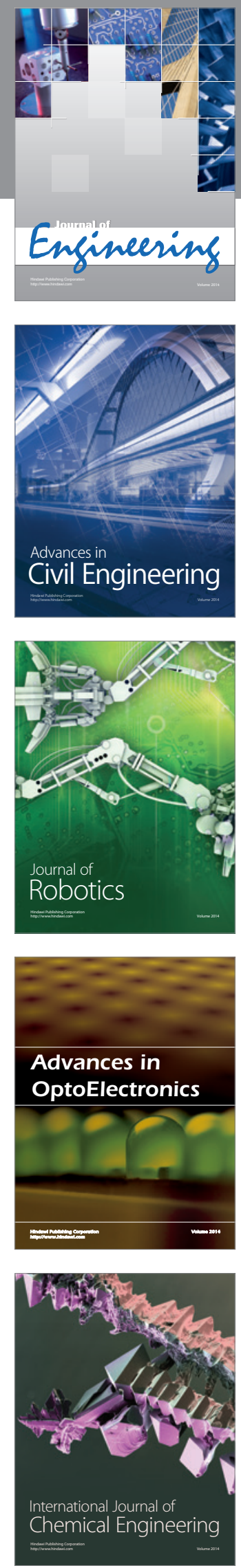

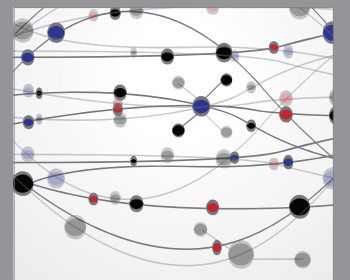

The Scientific World Journal
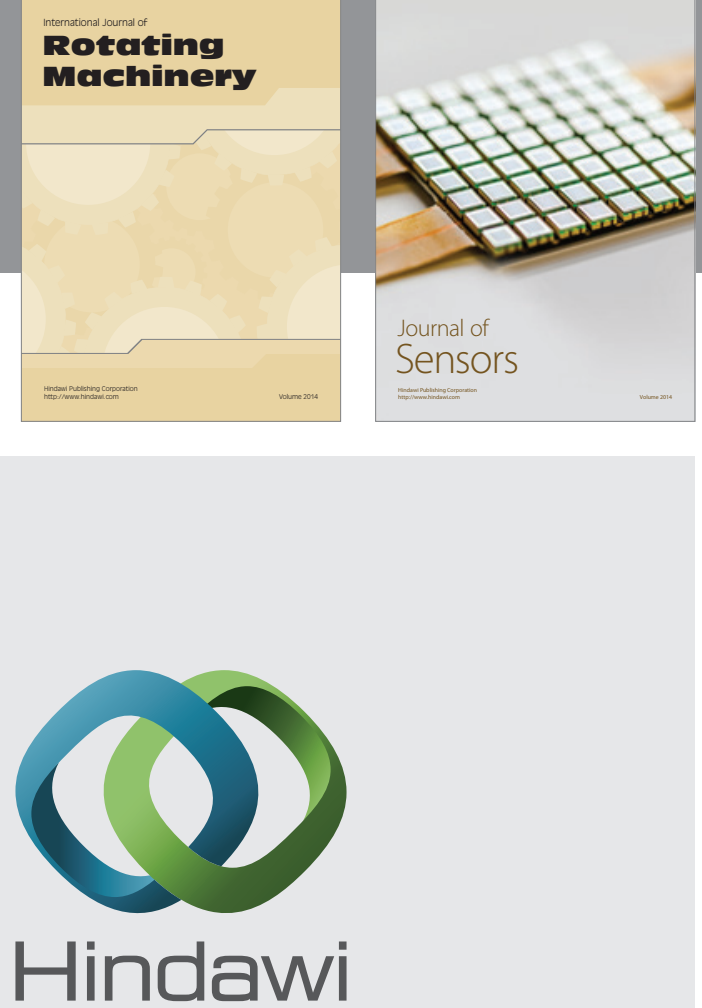

Submit your manuscripts at http://www.hindawi.com
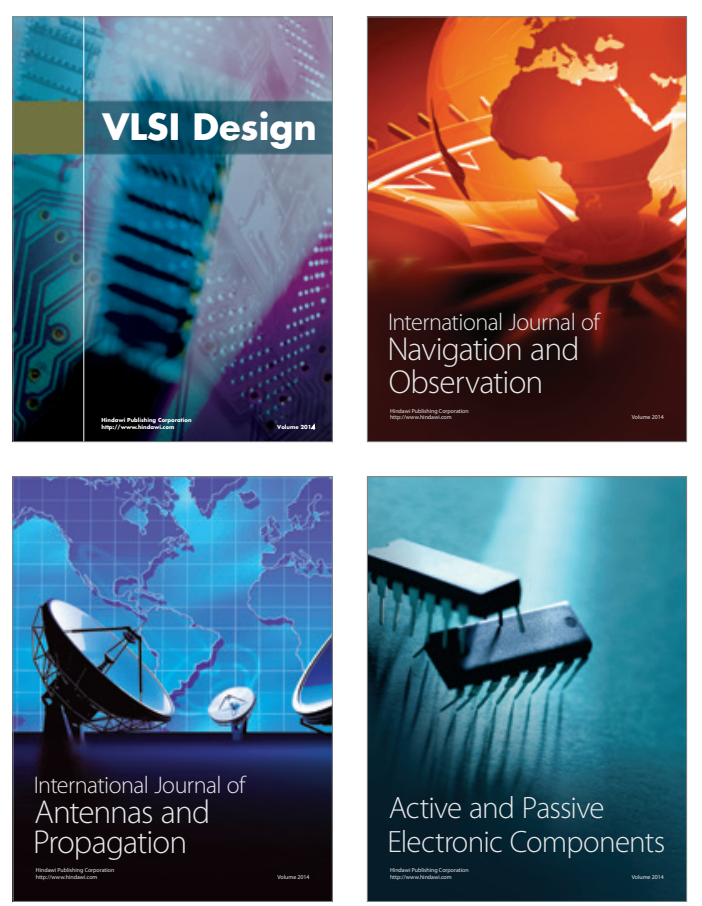
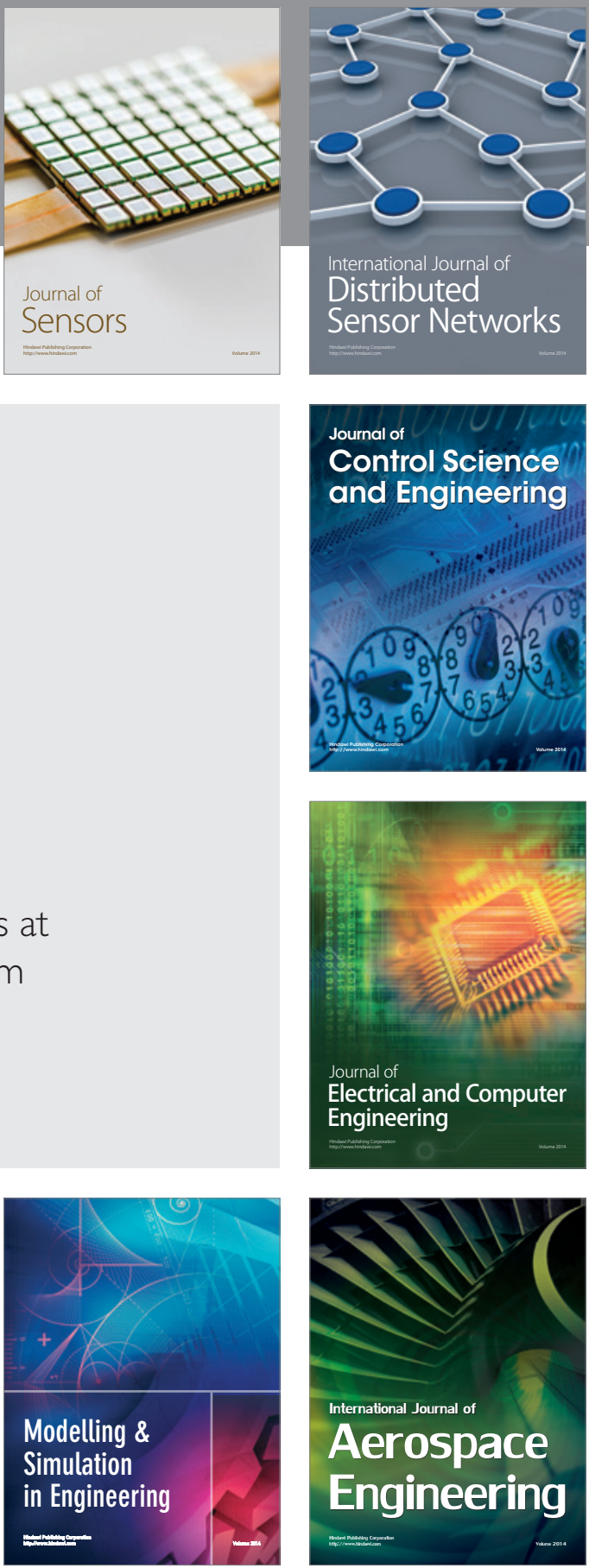

Journal of

Control Science

and Engineering
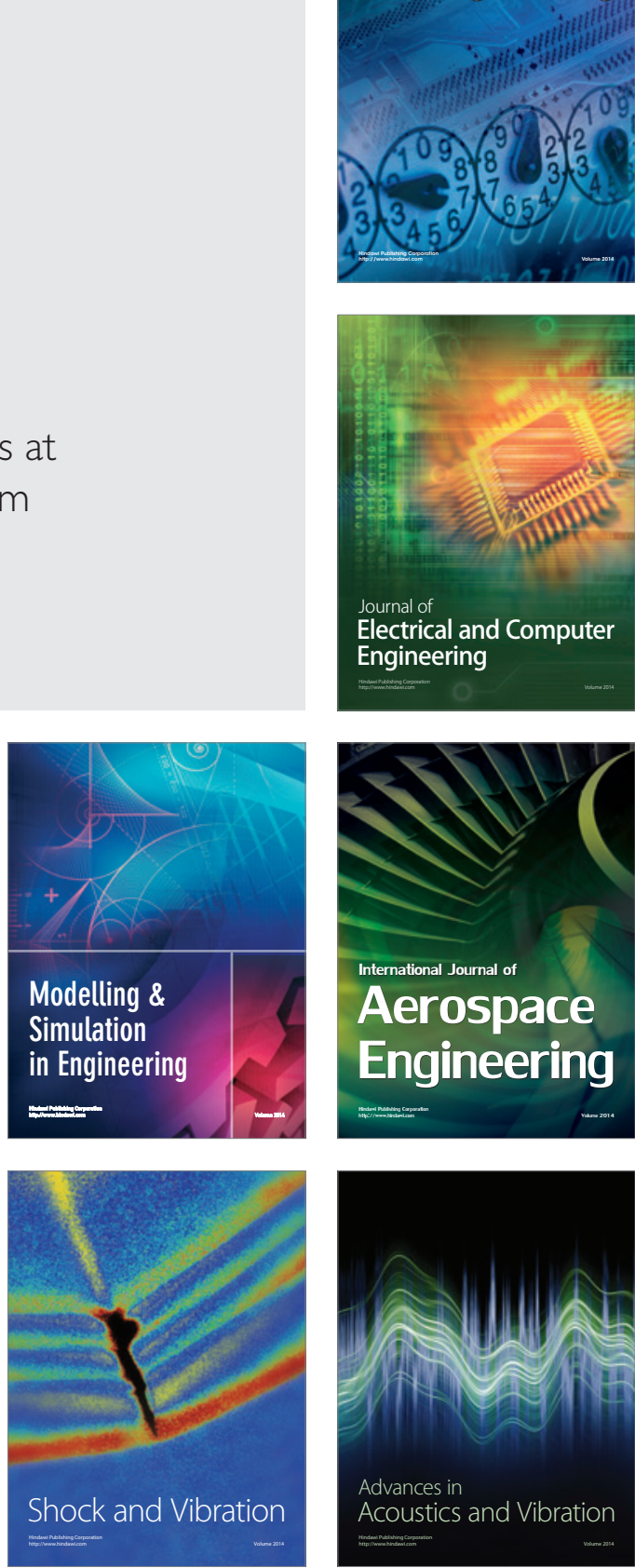